\title{
Environmental Degradation, Economic Growth and Non-renewable Energy in Selected South Asian Countries: Trivariate Analysis From DCCE-MG Approach
}

\section{Bosede Ngozi ADELEYE ( $\nabla$ ngozi.adeleye@covenantuniversity.edu.ng )}

Covenant University https://orcid.org/0000-0002-1274-714X

\section{Darlington AKAM}

University of Lagos

Nasiru INUWA

Gombe State University

Henry Tumba JAMES

Adamawa State University

Denis BASILA

Adamawa State University

Evans OSABUOHIEN

Covenant University

\section{Research Article}

Keywords: growth-led degradation, energy-led degradation, environmental degradation, South Asia

Posted Date: March 10th, 2021

DOI: https://doi.org/10.21203/rs.3.rs-256945/v1

License: (c) (i) This work is licensed under a Creative Commons Attribution 4.0 International License.

Read Full License 


\title{
Environmental degradation, economic growth and non-renewable energy in selected South Asian countries: Trivariate analysis from DCCE-MG approach
}

\begin{abstract}
This study investigates and provides evidence on the impact of economic growth and non-renewable energy on environmental degradation. Using unbalanced panel data from 1990 to 2018 on five South Asian countries and engaging the dynamic common correlated effects-mean group (DCCE-MG) technique of Ditzen $(2016,2018)$, findings support the energy-led degradation hypothesis while the growth-led degradation hypothesis does not hold but both are supported from FMOLS and DOLS robustness checks. In order words, non-renewable energy and economic growth significantly drive environmental degradation. Country-level results are mixed with Nepal evidencing energy-led degradation, Pakistan shows growth-led degradation while India indicates growth-led sustainability. Supportively, the Dumitrescu-Hurlin (2012) non-Granger causality test establishes: (1) energy-led and growth-led degradation, (2) feedback causal relation between environmental degradation and nonrenewable energy, and (3) unidirectional causality from growth to non-renewable energy i.e. "conservation" hypothesis. Policy implications are discussed.
\end{abstract}

Keywords: growth-led degradation, energy-led degradation, environmental degradation, South Asia 


\section{$1 \quad$ Introduction}

The drive to maintain a sustainable environment necessitated the 2030 United Nations Sustainable Development Goal (SDG) 13 agenda, which is to "take urgent action to combat climate change and its impacts". Therefore, to address climate change, it becomes imperative to understand its contributing factors: one of which is carbon dioxide $\left(\mathrm{CO}_{2}\right)$ emissions. The sources of carbon emissions are mainly from the burning of fossil fuel in a productive system with active power generation, transport, residential and industrial sectors (IPCC, 2018). These type of carbon emissions are known as "greenhouse" gases which should have been absorbed by space but are trapped by absorbing solar energy thereby heating the earth to cause global warming (National Geographic, 2019). This trapping of heat is known as the "greenhouse effect" which exemplifies environmental degradation.

Two key facts emanate from the illustrated scenario. First, the burning of fossil fuel evidences the usage of non-renewable energy which are divided into four components: coal, natural gas, oil, and nuclear energy. This combination not only alters the earth's atmosphere but also emit varieties of pollutants that negatively affect human health (IPCC, 2018). Secondly, the burning of fossil fuel typifies an active, vibrant and growing economy. In other words, non-renewable energy and economic growth are the identified drivers of environmental degradation, proxied by carbon emissions (Afridi, Kehelwalatenna, Naseem, \& Tahir, 2019; Dogan \& Aslan, 2017; Magazzino, 2016a; Murshed \& Dao, 2020; Nathaniel, Barua, Hussain, \& Adeleye, 2020; Osabuohien, Efobi, \& Gitau, 2014; Parker \& Bhatti, 2020; Shahbaz \& Sinha, 2018; Urhie, Afolabi, Afolabi, Matthew, Osabohien, Ewetan, \& Amoo, 2020). Hence, with the danger posed by increasing emissions, most developing economies are primarily saddled with the seemingly impossible task of curbing emissions amidst achieving steady economic growth and unhindered energy supply. The enormous threat posed by environmental degradation and the quest for economic growth and development, have further complicated the economic and environmental sustainability drive of developing economies, like those in South Asia. Given that environmental threat is heightened by the surge in global emissions and warming (IPCC, 2018), which pose an enormous danger to humans, marine life and the terrestrial ecosystem serves as the motivation for the examination of environmental degradation within a trivariate framework.

This study positions on South Asia which comprises of eight (8) countries: Afghanistan, Bangladesh, Bhutan, India, Nepal, The Maldives, Pakistan, and Sri Lanka based on three 
reasons: (1) pollution, (2) economic growth, and (3) energy demand. Firstly, according to IQAir (2019), South Asia is the most polluted region, with 27 of the 30 most polluted cities located therein. India inhabits 21 of those cities. For $\mathrm{PM}_{2.5}{ }^{1}$ using a weighted population average, Bangladesh emerges as the most polluted country followed by Pakistan, Mongolia, Afghanistan and India with deviations of less than $10 \%$ from one another. Among others, the surge in air pollution has adversely affected human health and tourist inflows with negative revenue and socio-economic shocks and spill-overs (TERI, 2019). Second, World Bank (2019a, 2019b) positioned the region as the fastest-growing region in the world though growth moderated from 7.2 percent in 2017 to 6.9 percent in 2018. Also, the countries have divergent economic outlooks which make comparativeness intrinsic. From United Nations (2019), in contrast to Pakistan, the economic conditions in Bangladesh, Bhutan and India are mostly positive with positive GDP growth projections. Lastly, energy demand is higher in Asia and projected to double between 2018 and 2050, making it both the largest and fastest-growing region in the world for energy consumption (EIA, 2019). Besides, India is one of the world's fastest-growing economies during much of the past decade, and they remain primary contributors to future growth in world energy demand (IEA, 2019a, 2019b).

The purpose of this study is to contribute to the empirical debate on whether economic growth and non-renewable energy demand trigger environmental degradation through the emissions of carbon dioxide in South Asia. To achieve this, an unbalanced panel data of per capita GDP (a proxy for economic growth), non-renewable energy per capita and carbon emissions per capita from five selected South Asian ${ }^{2}$ countries (Bangladesh, India, Nepal, Pakistan, and Sri Lanka) spanning 1990 to 2018 is used to: (1) investigate the growth-led and energy-led degradation relation; (2) assess if the growth-led and energy-led degradation relation significantly differ across the countries; and (3) establish the direction of causality among the variables. Similar to Shahbaz, Jam, Bibi, and Loganathan (2016), this paper further differs from previous studies on SAARC or South Asian countries (see Sharma, Kishan, and Doig (2014), Uddin and Wadud (2014), Pandey and Mishra (2015), Osmani (2018), Rahman, Saidi, and Mbarek (2020)) by strictly engaging a dynamic trivariate model to analyse the relationship. The possible endogeneity and dynamic nature of carbon emissions necessitate the need to employ a dynamic modelling approach. In other words, a dynamic model best captures the

\footnotetext{
${ }^{1}$ Fine particulate matter.

${ }^{2}$ Afghanistan, Bhutan, Maldives are dropped due to lack of sufficient data points.
} 
behaviour of an outcome which changes as a result of its past realisations. Hence, the study conjectures that carbon emissions respond to its past level(s), and the indicators of nonrenewable energy and per capita income. Given this, Ditzen $(2016,2018)$ dynamic common correlated effects-mean group (DCCE-MG ${ }^{3}$ ) approach which is an improvement on Chudik and Pesaran (2015) common correlated effects-mean group (CCE-MG) procedure is employed to address the first objective. This technique is justified because: (1) there is a possibility of cross-sectional dependence among the South Asian countries; (2) this study uses an unbalanced panel data; (3) carbon emissions is dynamic as the past levels are expected to influence future behaviours. Hereafter, the lagged dependent variable is included as a regressor; and (4) homogenous assumption of the slope coefficients since South Asian countries have some level of commonness such as common trade terms, monetary policies, and technologies. The DCCEpooled mean group (DCCE-PMG) technique is engaged for the second objective while for the third objective, the Dumitrescu-Hurlin (2012) Granger non-causality procedure is employed to determine the direction of causation between the variables. Lastly, for robustness, the dynamic ordinary least squares (DOLS) and fully modified ordinary least squares (FMOLS) techniques are deployed to ascertain if the results obtained via the DCCE-MG technique hold. The rest of the paper is structured as follows: section 2 reviews the empirical literature; section 3 outlines the data and empirical model; section 4 discusses the results, and section 5 concludes with policy recommendations.

\section{Review of Extant Literature}

Carbon emission is the proxy for environmental degradation, and the pursuit for a sustainable environment led to investigations on the drivers of carbon emissions. Several studies which will be highlighted in this section have explored different factors that aggravate environmental degradation with diverse outcomes partly due to the scope under coverage, the analytical technique and the choice of control variables. Therefore, without claim to being exhaustive, the carbon emissions literature is reviewed along with time series and panel data frameworks.

\section{$2.1 \quad$ Time series outcomes}

Covering the period 2005 to 2016, Ma, Wang, Dong, Gu, Chen, Li, and Li (2019) use a nonparametric procedure on the relation between carbon emissions and energy consumption to

\footnotetext{
${ }^{3}$ The Ditzen (2018) procedure also accommodates the pooled mean group variant for long-run homogenous slope coefficients. This assumption is invoked for the country-level analysis.
} 
conclude that economic growth is the primary predictor of carbon emissions in China. Analogous to Lin and Raza (2019) who find that energy intensity reduces carbon emissions in Pakistan for the period 1978 to 2017. Likewise, Shaheen, Sheng, Arshad, Salam, and Hafeez (2019) use the ARDL technique to show that in the long run, energy consumption and gross domestic product (GDP) intensify carbon emissions in Pakistan from 1972-2014. Salahuddin, Gowb, Ali, Hossain, Al-Azami, Akbar, and Ayfer (2019) use Zivot-Andrews breakpoint analysis to conclude that urbanisation and globalisation are the drivers of emissions in South Africa from 1980 to 2017. Similarly, Wang, Wang, Li, Fang, and Feng (2019) on China from 1995 to 2014 use the ridge analysis to reveal that population, urbanisation and industrialisation fuel carbon emissions. From 1970 to 2017, Sarkodie and Strezov (2018) deploy the dynamic autoregressive distributed lag (ARDL) model to reveal that energy consumption is a positive predictor of carbon emissions in Australia.

On Iran from 2002 to 2013 and using the dynamic ordinary least squares (DOLS) and vector error correction model (VECM) procedures, Shabani and Shahnazi (2019) conclude that growth, energy use and information technology are the drivers of carbon emissions. Also, Li, Zhou, and Wang (2019) use the fixed and random effects models to conclude that urbanisation, agro-tech and information technology are the major drivers of carbon emissions. On the study of Saudi Arabia from 1990 to 2015, Omri, Euchi, Hasaballah, and Al-Tit (2019) use the fully modified ordinary least squares (FMOLS) and DOLS to conclude that trade openness, financial development and foreign direct investment (FDI) are the principal contributors of carbon emissions. Similar to Okoye, Omankhanlen, Okoh, Adeleye, N., K., and Ehikioya (2021), Yang, Zhang, Xue, Ma, Chen, and Lu (2018) use the ARDL technique to find that trade openness and urbanisation drive emissions in China from 1995 to 2014. Sarkodie and Strezov (2018) conclude using FMOLS and DOLS that renewable energy stalls emissions in Australia from 1974 to 2013. Shahbaz, Shahzad, and Mahalik (2018) also use the ARDL approach to find that globalisation, energy use and economic growth exacerbate emissions in Japan from 1970 to 2014.

On Kuwait, Salahuddin, Alam, Ozturk, and Sohag (2018) deploy the ARDL, VECM, and DOLS techniques to find that the principal determinants of carbon emissions from 1980 to 2013 are FDI, energy use and economic growth. Likewise, Khan, Saleem, and Fatima (2018) deploy the FMOLS technique to find that financial development reduces emissions in India, Bangladesh, and Pakistan from 1980 to 2014. Zhou, Fu, Kong, and Wu (2018) find that FDI 
induces more carbon emissions in China from 2003 to 2015 using the ARDL technique. Roy, Basu, and Pal (2017) deploy the ridge technique on India from 1990 to 2016 and conclude that energy use reduces carbon emissions. Mirza and Kanwal (2017) from the VECM and ARDL procedures find a feedback relation between emissions/growth and emissions/energy use in Pakistan from 1979 to 2009. However, Bukhari and Waseem (2017) find a one-way causal impact from energy use to emission in Pakistan from 1972 to 2013 using the ARDL approach.

\subsection{Panel Data Outcomes}

Eurostat (2020) from the study of 27 member countries finds that carbon emission is a major contributor to global warming and account for some $80 \%$ of all human-made European Union (EU) greenhouse gas emissions. Shahbaz, Mahalik, Shahzad, and Hammoudeh (2019) deployed cross-correlation techniques to find that globalisation reduces carbon emissions from the study of 87 countries from 1970 to 2012 . The study validates the existence of the pollution haven hypothesis $(\mathrm{PHH})$, for the FDI/emissions and growth/emissions relations. Neagu and Teodoru (2019) use the DOLS and FMOLS procedures to show that a long-term equilibrium relationship exists among growth, energy use and greenhouse gas (GHG) emissions in $25 \mathrm{EU}$ countries. Churchill, Inekwe, Smyth, and Zhang (2019) on the study of G7 countries from 1870 to 2014, use a non-parametric approach to show that emissions and research and development exhibit time-varying features. Nguyen and Kakinaka (2019) deployed panel cointegration techniques in 107 countries from 1990 to 2013 to show that renewable energy stall carbon emissions in high-income countries. Correspondingly, Shahbaz, Balsalobre-Lorente, and Sinha (2019) use the generalised method of moments (GMM) technique to examine the association between FDI and carbon emissions for the Middle East and North African (MENA) region in 1990-2015.

From the analysis of high, middle, and lower-income countries, Azizalrahman (2019) use the ARDL procedure to find that urbanisation and energy consumption are the drivers of carbon emissions in high-income countries from 1973 to 2013. Using the quantile-on-quantile technique, Mallick, Padhan, and Mahalik (2019) find that the poor do not contribute to carbon emissions in the case of BRICS member-states from 1980 to 2014. Alike, Inglesi-Lotz (2018) use a non-parametric procedure on the study of BRICS member-states from 1990 to 2014 and finds that carbon emission is reduced with changes in energy and carbon intensity. This outcome is similar to Mahalik, Mallick, Padhan, and Sahoo (2018) who find that, except for Brazil, coal consumption drives carbon emission in BRICS member-states from 1980 to 2013. 
Equally, using a non-parametric approach, Chang, Dong, Sui, and Chu (2019) on analysing 121 countries show that population surge, energy consumption, economic growth and carbon intensity are the principal drivers of emissions from 2000 to 2014. Acheampong (2018) deploys the GMM and panel vector autoregressive (PVAR) techniques on a study of 116 countries from 1990 to 2014 to show that feedback causal relation exists between emissions/growth and emissions/energy use. Also, on a study of 17 countries from 1971 to 2013, Sarkodie (2018) deployed the fixed and random effects techniques to show that both globalisation and energy usage Granger-cause carbon emissions. On the study of 13 Asian countries from 1980 to 2010, Salim, Rafiq, and Shafiei (2017) deploy the augmented mean group (AMG) approach to show that trade liberalisation, urbanisation and renewable energy consumption reduce carbon emissions.

\section{$3 \quad$ Data and Model}

\subsection{Data}

This study employs an unbalanced annual panel data of selected five South Asian countries (Bangladesh, India, Nepal, Pakistan, and Sri Lanka) from 1990 to 2018. These countries are chosen subject to data availability. The dependent variable is carbon emissions $\left(\mathrm{CO}_{2}\right)$ measured in metric tons per capita. It is the proxy for environmental degradation (Alvarez-Herranz, Balsalobre-Lorente, Shahbaz, \& Cantos, 2017; Anatasia, 2015; Cetin \& Ecevit, 2017; Lorente \& A., 2016; Nathaniel \& Adeleye, 2021; Shahbaz, Lean , \& Shabbir, 2012). The independent variables are gross domestic product per capita $(P C)$ at constant $2010 \mathrm{US} \$$, and energy use $(E N U)$ measured as $\mathrm{kg}$ of oil equivalent per capita. All variables are sourced from World Bank (2019c) World Development Indicators database. The variable names, codes, sources, a priori expectations, descriptive statistics and correlation analysis are presented in Tables 1 and 2.

Table 1 Variables, Code, Source, and Expectations

\begin{tabular}{|l|c|c|c|}
\hline \multicolumn{1}{|c|}{ Variables } & Code & Source & Expectations \\
\hline Carbon emissions capita & $\mathrm{CO}_{2}$ & World Bank (2019) WDI & N/A \\
\hline GDP per capita & $P C$ & -do- & Positive \\
\hline Energy use per capita & $E N U$ & -do- & Positive \\
\hline
\end{tabular}

Note: $W D I=$ World Development Indicators; $N / A=$ Not Applicable Source: Authors' Compilation

From the outcomes shown in Table 3, the maximum $\mathrm{CO}_{2}$ emissions per capita is 1.724 emitted by India in 2014, while the lowest of 0.034 is traced to Nepal in 1990. With the mean value of 0.560 , the standard deviation of 0.385 does not suggest wide dispersion from the mean by 
countries in the sample. Similarly, per capita GDP has a mean score of US\$1,106.092 with minimum and maximum values of US\$3,936.45 and US\$354.258 from Sri Lanka in 2018 and Nepal in 1990, respectively. The standard deviation of 785,045 indicates wide dispersion from the sample mean. On average, non-renewable energy use per capita has a mean score of 366.577and a variability of 122.44. The maximum value of 636.57 is traced to India in 2014 while the lowest of 118.898 is from Bangladesh in 1991. Deductively, India's rising $\mathrm{CO}_{2}$ emissions is in tandem with the country's rate of non-renewable energy consumption. On the shape of the distribution, per capita GDP and $\mathrm{CO}_{2}$ exhibit positive skewness and kurtosis, while non-renewable energy consumption exhibits negative skewness but positive kurtosis suggesting a spike in the energy consumption of these countries.

\begin{tabular}{|c|c|c|c|}
\hline \multicolumn{4}{|c|}{ Descriptive Statistics and Correlation Matrix } \\
\hline Variable & $\mathrm{CO}_{2}$ Emissions & per capita GDP & Energy Use per capita \\
\hline \multicolumn{4}{|c|}{ Panel A: Descriptive Statistics } \\
\hline Mean & 0.560 & 1106.092 & 366.577 \\
\hline Maximum & 1.728 & 3936.45 & 636.570 \\
\hline Minimum & 0.034 & 354.258 & 118.898 \\
\hline Standard deviation & 0.385 & 785.045 & 122.440 \\
\hline Skewness & 0.686 & 1.893 & -0.499 \\
\hline Kurtosis & 3.030 & 6.329 & 2.585 \\
\hline \multicolumn{4}{|c|}{ Panel B: Correlation Matrix } \\
\hline $\mathrm{CO}_{2}$ Emissions & 1.000 & & \\
\hline per capita GDP & 0.390 & 1.000 & \\
\hline Energy Use & 0.746 & 0.540 & 1.000 \\
\hline
\end{tabular}

Source: Authors' Computations

The correlation analysis is performed to appraise the associations among the variables. Specifically, it is used to evaluate the strength of the linear relationship between the variables. From the lower panel, the correlation matrix shows that both per capita income and energy use have positive associations with the dependent variable, $\mathrm{CO}_{2}$ emissions per capita. Similarly, a positive association exists between the two regressors, and there is no evidence of collinearity that may lead to biased outcomes.

\subsection{Model Specification}

The present study investigates whether per capita income and energy use contribute or impede environmental degradation measured by the amount of carbon emissions in five selected South Asian countries from 1990 to 2018 . The empirical model is implicitly specified as:

$\mathrm{CO}_{2_{i t}}=f\left(P C_{i t}, E N U_{i t}\right)$ 
Where, $\mathrm{CO}_{2_{i t}}$ is carbon emissions per capita; $P C_{i t}$ is GDP per capita; and $E N U_{i t}$ is nonrenewable energy consumption per capita. Equation [1] is expressed in its explicit form, and the variables converted to their natural logarithms not only to control for outliers by removing large values that may create bias but primarily to establish elasticity relationships. The trivariate log-linear model is expressed as:

$\ln C O_{2 i t}=\beta_{0}+\beta_{1} \ln P C_{i t}+\beta_{2} \ln E N U_{i t}+\varepsilon_{i t}$

Where, In denotes the natural logarithm, $i$ represents the number of countries, $1,2, \ldots, N, t$ captures the time dimension $1,2, \ldots, T, \beta_{j}$ are the parameters interpreted as elasticities and $\varepsilon$ is the stochastic error term. From expectations, increase in per capita GDP should exacerbate carbon emissions and therefore deteriorate the environment. A rising income may lead to ostentatious living necessitating the consumption and production of goods, which may warrant the use of technologies that will provoke more carbon emissions. Similarly, an increase in nonrenewable energy use which is the practice of adopting non-replaceable energy sources such as coal, petroleum, natural gas, and fossil fuel contributes to rising carbon emissions and environmental degradation. Hence, positive coefficients are expected for both variables.

\section{$4 \quad$ Analytical Procedure and Results}

To address the study objectives, Equation [2] is analysed with a blend of analytical techniques which are deployed to investigate various aspects of the relation and to observe the consistency of the study outcomes. These techniques some of which have been used by similar studies (Ali, Anwar, \& Nasreen, 2017; Rahman et al., 2020; Yazdi \& Dariani, 2019) are discussed alongside their results in sequential order.

\subsection{Cross-Sectional Dependence (CSD) Test}

The empirical analysis starts with the application of the cross-sectional dependence test among the countries to determine the suitable methods to apply. The advantage of panel data analysis ranges from better degrees of freedom, greater efficiency of the estimates, and reduced occurrence of multicollinearity among the variables (Ditzen, 2016). However, the risk of crosssectionally dependent panels is very high due to the close proximities of the units and given the possibility of sharing common features. In the event of cross-sectional dependence (CSD) in the data, biased estimates and inferences will occur (Pesaran, 2004). To forestall such, the 
study engages the Pesaran $(2004,2007)^{4}$ test for cross-sectional dependency (CD) which can be applied to small and large panels. The null hypothesis of no CSD which can be rejected at the $1 \%, 5 \%$ and $10 \%$ significance levels is expressed as:

$C D=\sqrt{2 T / N(N-1)}\left(\sum_{i=1}^{N-1} \sum_{k=i+1}^{N} \hat{\rho}_{i, k}\right)$

The results of the CD test which is presented in Table 3 reject the null hypothesis of no crosssectional dependence at the $1 \%$ significance level suggesting that any shocks in one country may be transmitted to other countries among the South Asian countries.

Table 3 Cross-sectional Dependence Test

\begin{tabular}{lcc}
\hline Variable & CD-test & $p$-value \\
\hline $\mathrm{CO}_{2}$ per capita, $\log$ & $13.968^{\mathrm{a}}$ & 0.000 \\
per capita GDP, $\log$ & $16.822^{\mathrm{a}}$ & 0.000 \\
Energy per capita, $\log$ & $13.665^{\mathrm{a}}$ & 0.000 \\
\hline
\end{tabular}

Note: ${ }^{\text {a }}$ indicates the statistical significance at $1 \%$ level.

Source: Authors' Computations

\subsection{Slope Homogeneity Test}

On the other hand, the validity of the non-constancy of slope homogeneity in the coefficients among cross-sections instigates the importance of slope heterogeneity (Eberhardt \& Teal, 2012; Gunduz, 2017). For this reason, we employ the slope homogeneity test by Pesaran and Yamagata (2008). This test extends the Swamy (1970) test called the $\tilde{\Delta}$ test. While the former is applied to panels with relatively large/small cross-section $(N)$ to the time dimension $(T)$, the latter is applied to a cross-section that is relatively small to the time dimension. The modified version of Swamy's statistics is extended to both balanced and unbalanced data. The standardised statistics for unbalanced data is given by

$$
\tilde{\Delta}=\frac{1}{N} \sum_{i=1}^{N}\left(\frac{\hat{d}_{i}-K}{\sqrt{2 k}}\right)
$$

The test is asymptotically $\Delta \sim N(0,1)$ with a null hypothesis of slope homogeneity, and where $\mathrm{d}_{\mathrm{i}}$ in weighted form represents the difference between $N$ estimator and the pooled estimator $\left(\left(\hat{\beta}_{I}-\hat{\beta}_{W F E}\right)^{\prime} \frac{X_{i^{\prime} M_{t i} X_{i}}}{\hat{\sigma}^{2}}\left(\hat{\beta}_{I}-\hat{\beta}_{W F E}\right)\right)$. The test can be expressed in terms of normally

\footnotetext{
${ }^{4}$ Pesaran (2015) extends the analysis of the Pesaran (2004) CSD test and shows that the implicit null of the test is weak cross-sectional dependence. Interested reader is referred to Section 29.7 "Testing for error crosssectional dependence" in Pesaran, HM (2015) Time Series and Panel Data Econometrics, 1Ed., Oxford Press
} 
distributed errors using mean-variance bias-adjusted $\widehat{\Delta}$ (Bersvendsen and Ditzen (2020)) and it is expressed as:

$$
\tilde{\Delta}_{a d j}=\sqrt{N}\left(\frac{N^{-1} \sum_{i=1}^{N} \hat{d}_{i}-K}{\sqrt{\operatorname{Var}\left(\hat{z}_{i} T\right)}}\right)
$$

Where $\operatorname{Var}\left(\hat{z}_{i} T\right)$ equals $2 \mathrm{k}(\mathrm{T}-\mathrm{K}-1) /(\mathrm{T}-\mathrm{K}+1)$. The result of the slope homogeneity test, which rejects the null hypothesis of a homogeneous slope at the $1 \%$ level is presented in Table 4 . The outcome of the slope homogeneity test supports the engagement of the DCCE-MG technique for the individual countries.

Table 4 Slope Homogeneity Test

\begin{tabular}{cl}
\hline Delta & Model 1 \\
\hline$\tilde{\Delta}$ & $6.931^{\mathrm{a}}$ \\
$\tilde{\Delta}_{\text {adj }}$ & $7.562^{\mathrm{a}}$ \\
\hline
\end{tabular}

Null hypothesis $\left(\mathrm{H}_{0}\right)$ : slope coefficients are homogenous. Note: ${ }^{a}$ indicates the statistical significance at $1 \%$ level.

Source: Authors' Computations

\subsection{Panel Unit Root Tests}

Given the presence of cross-sectional dependence, the data is subjected to second-generation unit root tests to avoid spurious results. The cross-sectional augmented Im, Pesaran, and Shin (CIPS) and cross-sectional augmented Dickey-Fuller (CADF) tests developed by Pesaran (2007) are engaged. These techniques account for cross-sectional dependence among the constituent units. The equation for the CADF is stated as:

$\Delta y_{i t}=a_{i}+d_{i} y_{i, t-1}+c_{i} \bar{y}_{t-1}+b_{i} \Delta \bar{y}_{t}+u_{i, t}$

Where $z_{i t}$ represents the variable being tested. The CIPS test, which is the augmented variant of Im, Pesaran, and Shin (2003) unit root test, is expressed as:

$\operatorname{CIPS}(N, T)=\bar{T}=N^{-1} \sum_{i=1}^{N} t_{i}(N, T)$

Where $N$ and $T$ are the numbers of cross-sections and years, respectively. The left-hand side of Equation [7] is the unit root test for heterogeneous panels while on the right-hand side the term $t_{i}$ is the ordinary least squares (OLS) $t$-ratios employed in cross-sectional averaged 
augmented Dickey-Fuller (ADF) regression. The results of both the CADF and CIPS unit root tests are presented in Table 5 and indicate that all the variables are stationary at first difference.

\section{Table 5 Panel Unit Root Tests}

\begin{tabular}{lcc}
\hline Variable & CADF & CIPS \\
\hline Level & & \\
$\mathrm{CO}_{2}$ per capita, log & -0.913 & -1.489 \\
per capita GDP, log & -1.382 & -1.684 \\
Energy per capita, log & -1.250 & -1.250 \\
First differences & & \\
$\Delta \mathrm{CO}_{2}$ per capita, log & $-2.480^{\mathrm{b}}$ & $-5.058^{\mathrm{a}}$ \\
$\Delta$ per capita GDP, $\log$ & $-3.270^{\mathrm{a}}$ & $-4.423^{\mathrm{a}}$ \\
$\Delta$ Energy per capita, log & $-4.309^{\mathrm{a}}$ & $-4.309^{\mathrm{a}}$ \\
\hline
\end{tabular}

Note: ${ }^{\mathrm{a}}$ and ${ }^{\mathrm{b}}$ indicate statistical significance at $1 \%$ and $5 \%$ levels, respectively.

Source: Authors' Computations

\subsection{Panel Cointegration Tests}

To assess whether a long-run relationship exists among the variables, the second generation panel cointegration tests proposed by Westerlund (2007) is deployed. This technique is suitable in the presence of CSD in the data. The null hypothesis of no cointegration, which is rejected at the $1 \%$ and $5 \%$ significance levels are shown in Table 6 . These outcomes further assert the presence of long-run cointegrating relationship among the variables. Hence, there exists a longrun relationship between energy consumption, economic growth (income), and environmental degradation $\left(\mathrm{CO}_{2}\right.$ emissions) in the South Asian region.

Table 6 Westerlund Panel Cointegration Test

\begin{tabular}{ccc}
\hline Panel Westerlund Cointegration & Test Statistic & Robust $p$-value \\
\hline $\mathrm{Gt}$ & $-3.148^{\mathrm{a}}$ & 0.000 \\
$\mathrm{Ga}$ & $-9.645^{\mathrm{b}}$ & 0.020 \\
$\mathrm{Pt}$ & $-6.747^{\mathrm{b}}$ & 0.040 \\
$\mathrm{~Pa}$ & -6.090 & 0.300 \\
\hline
\end{tabular}

Note: ${ }^{\mathrm{a}, \mathrm{b}}$, and ${ }^{\mathrm{c}}$ indicate statistical significance at $1 \%, 5 \%$, and $10 \%$ levels, respectively.

Source: Authors' Computations

\subsection{Dynamic Common Correlated Effects-Mean Group}

To address the first study objective of testing for long-run relationship among the variables for the full sample, the DCCE-MG technique proposed by Ditzen $(2016,2018)$ is adopted for several reasons: (1) it accounts for both heterogeneous and homogeneous coefficients, (2) controls for cross-sectional dependence; (3) supports instrumental variable regressions; (4) suitable for unbalanced panels; (5) corrects for small sample bias (6) uses the jack-knife correction method and the recursive mean adjustment (Chudik \& Pesaran, 2015; Pesaran, 
2006). This technique is important because it helps in identifying effects for each cross-section separately and account for unobserved dependencies between the units. The DCCE-MG equation is specified as:

$y_{i, t}=\lambda_{i} y_{i, t-1}+\beta_{i} x_{i, t}+\sum_{I=0}^{P T} \delta_{i, I}^{\prime} \bar{z}_{t-I}+\epsilon_{i, t}$

Where, $\bar{Z}_{t}=\left(\bar{y}_{t} \bar{y}_{t-1}, \bar{x}_{t}\right)$. Thus, the Mean Group estimates are: $\hat{\pi}_{M G}=\frac{1}{N} \sum_{i=1}^{N} \hat{\pi}_{i}=\left(\hat{\lambda}_{i}, \hat{\beta}_{i}\right)$. The assumption of a long-run homogeneous slope is conditioned for the full sample while that of long-run slope heterogeneity is assumed for the individual country analysis based on the outcome of the Pesaran and Yamagata (2008) slope homogeneity test in Table 4. The results of the DCCE-MG analysis shown in Table 7 reveal a statistically significant positive elasticity effect of the past level of $\mathrm{CO}_{2}$ emissions and contemporaneous energy consumption on $\mathrm{CO}_{2}$ emissions at the $5 \%$ and $1 \%$ levels, respectively. It implies that a percentage change in the previous year's emissions level is associated with an increase in $\mathrm{CO}_{2}$ emissions by 0.175 per cent, on average, ceteris paribus. This also indicates that carbon emissions is rising in the selected countries, which by extension implies the persistency of environmental degradation. This outcome contradicts Aye, Edoja, and Charfeddine (2017) who found a positive but insignificant relation and Ghazali and Ali (2019) that indicate negative and significant previous year's emissions on the current $\mathrm{CO}_{2}$ emissions, respectively.

Table 7 DCCE-MG Results

\begin{tabular}{|c|c|}
\hline Variables & $\mathrm{CO}_{2}$ \\
\hline $\mathrm{CO}_{2}$ per capita_1, log & $0.175^{\mathrm{b}}(2.47)$ \\
\hline Energy per capita, log & $1.009^{\mathrm{a}}$ '(4.99) \\
\hline per capita GDP, log & $0.16(0.22)$ \\
\hline
\end{tabular}

The outcomes further suggest that the use of non-renewable energy exacerbates environmental degradation. It shows that the latter exerts a statistically significant positive impact (1.009) on carbon emissions at the $1 \%$ level, on average, ceteris paribus. The magnitude of impact indicates a one-for-one elasticity relationship such that if the usage of non-renewable energy increases by $100 \%$ in South Asian countries, carbon emissions level will rise by $100 \%$ which further endangers the environment supporting the energy-led degradation hypothesis. Our findings support related studies (Afridi et al., 2019; Magazzino, 2016b; Nathaniel et al., 2020; 
Neagu \& Teodoru, 2019). On the other hand, there is no evidence to support the growth-led degradation as economic growth proxied by per capita GDP does not exert any statistically significant effect on $\mathrm{CO}_{2}$ emissions, though the coefficient is positive. This outcome suggests there is no evidence that economic growth aggravates environmental degradation. In retrospect, the non-significant but positive impact of economic growth on $\mathrm{CO}_{2}$ emissions may indicate inadequate growth in these selected countries not sufficient to trigger environmental degradation. Similar to other studies (see Ozturk and Acaravci (2013); Salahuddin, Alam, and Ozturk (2016)) with no evidence of growth-led degradation.

\subsection{Dynamic OLS and Fully Modified OLS}

To test for the robustness of our findings, the FMOLS and DOLS techniques are used. The DOLS is a parametric approach in which lags and leads are introduced to cope with the problem of cross-sectional dependence irrespective of the order of integration and the existence or absence of cointegration. At the same time, the FMOLS is a non-parametric approach used to dealing with serial correlation. Kao and Chiang (2001) extended the DOLS technique to panel data analysis with the following model specification:

$y_{i, t}=\beta_{i}^{\prime} x_{i, t}+\sum_{j=-q}^{q} \delta_{i j} \Delta x_{i, t+j}+\gamma l i^{\prime} D l_{i}+\varepsilon_{i, t}$

Where, $q$ refers to the number of lags chosen using the appropriate information criteria. The DOLS is suitable for this study because it provides a robust correction of endogeneity in the regressors. Similarly, the use of FMOLS panel data analysis was introduced by Pedroni (1999, 2001). This technique not only gives consistent estimates of the parameters in small sample data but also controls for likely endogeneity of the regressors and serial autocorrelation. Ramirez (2006) simplifies the FMOLS estimator for the $i$-th unit as:

$\beta_{i}^{*}=\left(X_{i}{ }^{\prime} X_{i}\right)^{-1}\left(X_{i}{ }^{\prime} y_{i}^{*}-\mathrm{T} \boldsymbol{\delta}\right)$

Where, $y^{*}$ connotes the transformed endogenous variable, $\delta$ is the parameter for autocorrelation adjustment, and $T$ is the number of periods. The results from the FMOLS, and DOLS techniques are presented in Table 8 and indicate that economic growth intensifies $\mathrm{CO}_{2}$ emissions by 0.61 and 0.29 percent, respectively. Similarly, energy is found to provoke emissions by 0.96 and 1.46 percent, respectively in the long-run and all the relationships are 
statistically significant at the $1 \%$ level. More so, the evidence is given that both growth-led and energy-led degradation are prevalent in South Asia.

Table 8 FMOLS and DOLS Results

\begin{tabular}{lcc}
\hline Variables & \multicolumn{1}{c}{ FMOLS } & DOLS \\
\cline { 2 - 3 } & $\mathrm{CO}_{2}$ & $\mathrm{CO}_{2}$ \\
\hline Energy per capita, log & $0.962^{\mathrm{a}}(27.486)$ & $1.464^{\mathrm{a}}(7.431)$ \\
per capita GDP, $\log$ & $0.608^{\mathrm{a}}(86.857)$ & $0.286^{\mathrm{b}}(2.252)$ \\
\hline Note: ${ }^{\mathrm{a}, \mathrm{b}}$, and & c indicate statistical significance at $1 \%, 5 \%$, and $10 \%$ levels, \\
respectively; $t$-statistics are in ( ). &
\end{tabular}

In general, the results from the DOLS and FMOLS analysis are in tandem with those of DCCEMG, except for per capita GDP that is statistically not significant. This could be because the DCCE-MG technique controls for dependence among these selected South Asian countries. Hence, reliance on the results of the DOLS and FMOLS techniques alone may give flawed and ambiguous outcomes, given the likelihood of common shocks permeating across the countries.

Furthermore, the outcome of the slope homogeneity test supports the use of the DCCE-MG approach for the individual countries. That is, it provides sufficient evidence for heterogeneous slopes for the countries. As a result, Equation [9] is augmented to accommodate country-level analysis, and the results are indicated in Table 9.

Table 9 DCCE-PMG Country-level Results

\begin{tabular}{lccccc}
\hline \multirow{2}{*}{ Variables } & Bangladesh & India & Nepal & Pakistan & \multicolumn{2}{c}{ Sri Lanka } \\
\cline { 2 - 6 } & $\mathrm{CO}_{2}$ & $\mathrm{CO}_{2}$ & $\mathrm{CO}_{2}$ & $\mathrm{CO}_{2}$ & $\mathrm{CO}_{2}$ \\
\hline $\mathrm{CO}_{2}$ per capita_1, log & $0.173(1.37)$ & $-0.045^{\mathrm{a}}(-9.71)$ & $0.108(0.69)$ & $0.268(1.15)$ & $0.373(0.31)$ \\
Energy per capita, log & $1.452(0.42)$ & $0.91(0.71)$ & $0.281^{\mathrm{b}}(2.11)$ & $1.143(0.57)$ & $1.262(0.39)$ \\
per capita GDP, log & $-1.726(-1.39)$ & $-0.087^{\mathrm{a}}(-10.27)$ & $2.832(0.36)$ & $0.223^{\mathrm{a}}(3.64)$ & $-1.444(-0.49)$ \\
\hline
\end{tabular}

Note: ${ }^{\mathrm{a},}$ and ${ }^{\mathrm{b}}$ indicate statistical significance at $1 \%, 5 \%$, and $10 \%$ levels, respectively; $t$-statistics in ( ).

Source: Authors' Computations

Firstly, we find no evidence of continual environmental degradation in Bangladesh, Nepal, Pakistan, and Sri Lanka as the coefficient of the lagged $\mathrm{CO}_{2}$ emissions is positive but not statistically significant suggesting that past $\mathrm{CO}_{2}$ emissions is inadequate to deteriorate the environment in these countries. Contrarily, India shows a negative and statistically significant impact of its past emissions on contemporaneous level of $\mathrm{CO}_{2}$ emissions at the $1 \%$ level (see also Ghazali and Ali (2019); Shaari, Karim, and Abidin (2020)). It implies that the past 
emissions level do not adversely contribute to environmental degradation. The most plausible reasoning could be the gradual departure from using non-renewable energy sources to environmentally friendly energy sources. In a different sublet, per capita GDP shows a statistically significant negative (-0.087) impact on $\mathrm{CO}_{2}$ emissions at the $1 \%$ level in India but a statistically significant positive (0.223) impact in Pakistan, also at the $1 \%$ level. These outcomes suggest that a percentage change in per capita GDP reduces the emissions level in India by 0.08 percent. In comparison, it increases that of Pakistan by 0.223 percent, on average, ceteris paribus. Hence, the growth-led sustainability holds for India while growth-led degradation holds for Pakistan. Further points reveal that non-renewable energy tends to exert harmful effects on the environment in South Asia, though the impact is statistically not significant, except in Nepal. This indicates that energy consumption contributes significantly to environmental degradation in Nepal, implying a more severe and harmful environment emanating from the energy source in the country instituting the energy-led degradation stance.

\subsection{Dumitrescu-Hurlin non-Causality Test}

Finally, this study addresses the fourth objective which is to establish the direction of causality between the variables by deploying Dumitrescu and Hurlin (2012) causality tests (hereafter, referred to as D-H) which are shown in Table 10. The D-H technique is adopted because it accommodates heterogeneity and cross-sectional dependence among the constituent units that make up the panel which other Granger causality test do not have. Similarly, the technique is capable of providing reliable estimates for small sample data. Danish, Ulucak, and Khan (2019) constructs the D-H model as:

$Y_{i, t}=\delta_{i}+\sum_{i=1}^{P} \gamma_{i}^{(\rho)} X_{i, t-n}+\sum_{i=1}^{P} \varphi_{i}^{(\rho)} Y_{i, t-n}+\varepsilon_{i, t}$

Where, $n$ implies the lag length, $X$ and $Y$ are the variables in the panel for $n$ cross-sections in

time $t, \gamma_{i}^{(\rho)}$ and $\varphi_{i}^{(\rho)}$ connote the autoregressive parameters and regression coefficient across the constituent units. The hypotheses that guide the DH model are given as:

$H_{0}: \gamma_{i}=\cdots \gamma_{p}=0 \quad \forall_{i}=1,2, \ldots, N$

Against the alternative:

$H_{i}: \gamma_{i} \neq \cdots \gamma_{p} \neq 0 \quad \forall_{i} \neq 1,2, \ldots, N$ 
Table $10 \quad$ Causality Results

\begin{tabular}{llc}
\hline Equation Variables & Excluded Variables & W-stat \\
\hline $\mathrm{CO}_{2}$ per capita & per capita GDP & $3.628^{\mathrm{a}}$ \\
& Energy per capita & $2.456^{\mathrm{c}}$ \\
per capita GDP & & \\
& $\mathrm{CO}_{2}$ per capita & 0.179 \\
& Energy per capita & 0.766 \\
Energy per capita & & $3.11^{\mathrm{a}}$ \\
& $\mathrm{CO}_{2}$ per capita & $6.287^{\mathrm{a}}$ \\
\hline Note: Ho: Excluded variable does not Granger-cause Equation variable; Ha: \\
\multicolumn{2}{l}{ Excluded variable Granger-causes Equation variable; ${ }^{\mathrm{a}}(\mathrm{p}<0.01),{ }^{\mathrm{b}}(\mathrm{p}<0.05)$, and $^{\mathrm{c}}$} \\
(p<0.1) indicate statistical significance at the 1\%, 5\%, and 10\% levels respectively. \\
\multicolumn{2}{l}{ Source: Authors' Computations }
\end{tabular}

Table 10 details the result from the Dumitrescu-Hurlin test, which reveals a one-way causal relation from economic growth to environmental degradation ("growth-led degradation"). Hence, it is inferred that economic growth promotes environmental deterioration. Also, the results reveal a bi-directional relationship between non-renewable energy and environmental degradation ("feedback hypothesis" and "energy-led degradation"). This outcome implies that the previous value of energy consumption is significant enough to explain the future dynamics of environmental degradation with feedback effects. Further, the results exhibit a one-way causality from economic growth to non-renewable energy ("conservation hypothesis"), indicating that as economies grow energy consumption increases.

\section{$5 \quad$ Conclusion and Policy Implications}

The relationship among environmental degradation proxied by carbon dioxide emissions, nonrenewable energy, and per capita GDP for the past few decades has fuelled a series of debates with attracted attention across the globe. As such, this study contributes to the debate by engaging an unbalanced panel data of five selected South Asian countries (Bangladesh, India, Nepal, Pakistan, and Sri Lanka) covering 1990 to 2018. Our results provide sufficient evidence to address the study objectives. That is: (1) energy-led and growth-led degradation exist in the data; (2) the results from the individual countries are significantly different with Nepal indicating energy-led degradation, Pakistan with growth-led degradation and India with growth-led sustainability; and (3) economic growth Granger-causes energy use and environmental degradation (unidirectional causality) while a bi-directional causal relation obtains between degradation and non-renewable energy. 
Policy implications derived are not far-fetched. The finding above does not provide only concerted information for policymakers in these countries, but individual details for each country's stakeholders since the evidence of heterogeneity implies that each nation in the panel of the selected region (South Asia) may develop its environmental easing policies. Also, the stakeholders should collectively put in place effective energy management in charge of reducing the negative effect of energy-consuming industries and energy-consuming technologies to ensure pollution easing in these countries. Further, the rising income from economic growth by these countries should be devoted to acquiring resources that will minimise environmental damage and, in turn, boost output.

Lastly, tackling climate change and ensuring a sustainable environment (SDG13) requires that de-carbonisation measures be pursued to enable a healthy environment that will reduce health impacts due to energy-related air pollution (SDG3) by 2030. However, there exists a dilemma for developing economies like those of South Asia who may require a trade-off. This is because the drive to pursue economic growth agendas will elicit more carbon emissions which will further degrade the environment. We leave this open for more constructive policy discourse on the quagmire of growth-led degradation.

\section{Declaration:}

Ethics approval and consent to participate: Not Applicable

Consent for publication: Not Applicable

Availability of data and materials: The datasets used and/or analysed during the current study are available from the corresponding author on reasonable request.

Competing interests: "The authors declare that they have no competing interests"

Funding: Not Applicable

Authors' contributions: "BNA conceptualized, prepared the original draft, supervised; DA analysed and interpreted the data; NI analysed and interpreted the data; HTJ contributed to the methodology; DB contributed to the literature review; EO critiqued the manuscript; All authors read and approved the final manuscript."

\section{References}

Acheampong, A. O. (2018). Economic Growth, CO2 Emissions and Energy Consumption: What Causes What and Where? Energy Economics, 74, 677-692.

Afridi, M. A., Kehelwalatenna, S., Naseem, I., \& Tahir, M. (2019). Per capita Income, Trade Openness, Urbanization, Energy Consumption, and CO2 Emissions: An Empirical Study on the SAARC Region. Environmental Science Pollution Research, 26(6), 29978-29990. doi:10.1007/s11356-019-06154-2

Ali, S., Anwar, S., \& Nasreen, S. (2017). Renewable and Non-Renewable Energy and its Impact on Environmental Quality in South Asian Countries. 
Alvarez-Herranz, A., Balsalobre-Lorente, D., Shahbaz, M., \& Cantos, J. M. (2017). Energy Innovation and Renewable Energy Consumption in the Correction of Air Pollution Levels. Energy Policy, 105, 386-397.

Anatasia, V. (2015). The Causal Relationship between GDP, Exports, Energy Consumption, and CO2 in Thailand and Malaysia. International Journal of Economic Perspectives, 9(4), 37-48.

Aye, G. C., Edoja, P. E., \& Charfeddine, L. (2017). Effect of Economic Growth on CO2 Emission in Developing Countries: Evidence from a Dynamic Panel Threshold Model. Cogent Economics \& Finance, 5(1), 1-22. doi:10.1080/23322039.2017.1379239

Azizalrahman, H. (2019). A Model for Urban Sector Drivers of Carbon Emissions. Sustainable Cities and Society, 44, 46-55.

Bersvendsen, T., \& Ditzen, J. (2020). Xthst: Testing for Slope Homogeneity in Stata. Centre for Energy Research and Policy, Working Paper No 11.

Bukhari, N., \& Waseem, M. (2017). Impact of Energy Consumption on CO2 Emissions: Case of Pakistan. Journal of Management Information, 4(1), 1-5.

Cetin, M., \& Ecevit, E. (2017). The Impact of Financial Development on Carbon Emissions under the Structural Breaks: Empirical Evidence from Turkish Economy. Intenational Journal of Economic Perspectives, 11(1), 64-78.

Chang, C. P., Dong, M., Sui, B., \& Chu, Y. (2019). Driving Forces of Global Carbon Emissions: from Time-and Spatial-Dynamic Perspectives. Economic Modelling.

Chudik, A., \& Pesaran, M. H. (2015). Common Correlated Effects Estimation of Heterogeneous Dynamic Panel Data Models with Weakly Exogenous Regressors. Journal of Econometrics, 188(2), 393-420.

Churchill, S. A., Inekwe, J., Smyth, R., \& Zhang, X. (2019). R\&D Intensity and Carbon Emissions in the G7: 1870-2014. Energy Economics, 80, 30-37.

Danish, Ulucak, R., \& Khan, S. U.-D. (2019). Determinants of the Ecological Footprint: Role of Renewable Energy, Natural Resources, and Urbanization. Sustainable Cities and Society, 54, 101996. doi:10.1016/j.scs.2019.101996

Ditzen, J. (2016). xtdcce2: Estimating Dynamic Common Correlated Effects in Stata. In E. HeriotWatt University, UK (Ed.), Spatial Economics and Econometrics Centre (SEEC) (pp. 1-26): Heriot-Watt University.

Ditzen, J. (2018). Estimating Dynamic Commom-Correlated Effects in Stata. The Stata Journal, 18(30), 585-617. doi:10.1177/1536867X0600600403

Dogan, E., \& Aslan, A. (2017). Exploring the Relationship among CO2 Emissions, Real GDP, Energy Consumption and Tourism in the EU and Candidate Countries: Evidence from Panel Models Robust to Heterogeneity and Cross-sectional Dependence. Renewable and Sustainable Energy Reviews, 7(C), 239-245.

Dumitrescu, E. L., \& Hurlin, C. (2012). Testing for Granger Non-causality in Heterogeneous Panels. Economic Modelling, 29(4), 1450-1460.

Eberhardt, M., \& Teal, F. (2012). Structural Change and Cross-Country Growth Empirics. World Bank Economic Review, 27(2), 229-271.

EIA. (2019). International Energy Outlook 2019: With Projections to 2050. Retrieved from US Energy Information Administration: www.eia.gov/ieo

Eurostat. (2020). CO2 Emissions from Energy Use. Retrieved from

Ghazali, A., \& Ali, G. (2019). Investigation of Key Contributors of CO2 Emissions in Extended STIRPAT Model for Newly Industrialised Countries: A Dynamic Common Correlated Estimator (DCCE) Approach. Energy Reports, 5, 242-252.

Gunduz, H. I. (2017). Testing for Slope Homogeneity in Dynamic Panel Using the Wild Bootstrap Test. Ekonometric ve Istatistik Sayi, 26, 53-59.

IEA. (2019a). Southeast Asia Energy Outlook 2019. Retrieved from International Energy Agency: www.iea.org

IEA. (2019b). World Energy Outlook 2019. Retrieved from International Energy Agency: www.iea.org

Im, K. S., Pesaran, M. H., \& Shin, Y. (2003). Testing for Unit Roots in Heterogeneous Panels. Econometrics, 115(1), 53-74. 
Inglesi-Lotz, R. (2018). Decomposing the South African CO2 Emissions Within a BRICS Countries Context: Signalling Potential Energy Rebound Effects. Energy, 147, 648-654.

IPCC. (2018). Sources of CO2. In J. Gale, J. Bradshaw, Z. Chen, A. Garg, D. Gomez, H.-H. Rogner, D. Simbeck, R. Williams, F. Toth, D. van Vuuren, I. El Gizouli, \& J. F. Hake (Eds.), IPCC Special Report on Carbon Dioxide Capture and Storage (pp. 75-105): IPCC.

IQAir. (2019). World Air Quality Report: Region and City PM2.5 Ranking. Retrieved from IQAir AirVisual:

Khan, A. Q., Saleem, N., \& Fatima, S. T. (2018). Financial Development, Income Inequality, and CO 2 Emissions in Asian Countries Using STIRPAT Model. Environmental Science and Pollution Research, 25(7), 6308-6319.

Li, S., Zhou, C., \& Wang, S. (2019). Does Modernization Affect Carbon Dioxide Emissions? A Panel Data Analysis. Science of the Total Environment.

Lin, B., \& Raza, M. Y. (2019). Analysis of Energy Related CO2 Emissions in Pakistan. Journal of Cleaner Production.

Lorente, D. B., \& A., A.-H. (2016). Economic Growth and Energy Regulation in the Environmental Kuznets Curve. Environmental Science Pollution Research, 23, 16478-16494.

Ma, X., Wang, C., Dong, B., Gu, G., Chen, R., Li, Y., et al. (2019). Carbon Emissions from Energy Consumption in China: Its Measurement and Driving Factors. Science of the Total Environment, 648, 1411-1420.

Magazzino, C. (2016a). CO2 Emissions, Economic Growth, and Energy Use in the Middle East Countries: A panel VAR Approach. Energy Sources, Part B: Economics, Planning, and Policy, 11(10), 960-968. doi:10.1080/15567249.2014.940092

Magazzino, C. (2016b). The Relationship between Real GDP, CO2 Emissions, and Energy Use in the GCC Countries: A Time Series Approach. Cogent Economics \& Finance, 4(1152729), 1-20. doi:10.1080/23322039.2016.1152729

Mahalik, M. K., Mallick, H., Padhan, H., \& Sahoo, B. (2018). Is Skewed Income Distribution Good for Environmental Quality? A Comparative Analysis Among Selected BRICS Countries.

Environmental Science and Pollution Research, 25(23), 23170-23194.

Mallick, H., Padhan, H., \& Mahalik, M. K. (2019). Does Skewed Pattern of Income Distribution Matter for the Environmental Quality? Evidence from Selected BRICS Economies with an Application of Quantile-on-Qauntile Regression (QQR) Approach. Energy Policy, 129, 120131.

Mirza, F. M., \& Kanwal, A. (2017). Energy Consumption, Carbon Emissions and Economic Growth in Pakistan: Dynamic Causality Analysis. Renewable and Sustainable Energy Reviews, 72, 1233-1240.

Murshed, M., \& Dao, N. T. T. (2020). Revisiting the CO2 Emission-induced EKC Hypothesis in South Asia: The role of Export Quality Improvement. GeoJournal. doi:https://doi.org/10.1007/s10708-020-10270-9

Nathaniel, S., Barua, S., Hussain, H., \& Adeleye, N. (2020). The Determinants and Interrelationship of Carbon Emissions and Economic Growth in African Economies: Fresh Insights from Static and Dynamic Models. Journal of Public Affairs, e2141, 1-15. doi:10.1002/pa.2141

Nathaniel, S. P., \& Adeleye, N. (2021). Environmental Preservation amidst Carbon Emissions, Energy Consumption, and Urbanization in Selected African Countries: Implication for Sustainability. Journal of Cleaner Production, 1-33. doi:https://doi.org/10.1016/j.jclepro.2020.125409

National Geographic. (2019). Carbon Dioxide Levels are at a Record High. Here's What You Need to Know. Retrieved from https://www.nationalgeographic.com/environment/globalwarming/greenhouse-gases/

Neagu, O., \& Teodoru, M. C. (2019). The Relationship between Economic Complexity, Energy Consumption Structure and Greenhouse Gas Emission: Heterogeneous Panel Evidence from the EU Countries. Sustainability, 11(497), 1-29. doi:10.3390/su11020497

Nguyen, K. H., \& Kakinaka, M. (2019). Renewable Energy Consumption, Carbon Emissions, and Development Stages: Some Evidence from Panel Cointegration Analysis. Renewable Energy, $132,1049-1057$. 
Okoye, L. U., Omankhanlen, A. E., Okoh, J. I., Adeleye, N. B., N., E. F., K., E. G., et al. (2021). Analyzing the Energy Consumption and Economic Growth Nexus in Nigeria. International Journal of Energy Economics and Policy, 11(1), 378-387. doi:https://doi.org/10.32479/ijeep.10768

Omri, A., Euchi, J., Hasaballah, A. H., \& Al-Tit, A. (2019). Determinants of Environmental Sustainability: Evidence from Saudi Arabia. Science of the Total Environment, 657, 1592-1601.

Osabuohien, E. S., Efobi, U. R., \& Gitau, C. M. W. (2014). Beyond the Environmental Kuznets Curve in Africa: Evidence from Panel Cointegration. Journal of Environmental Policy \& Planning, 16(4), 517-538.

Osmani, S. R. (2018). Socio-economic development in South Asia. Retrieved from United Nations University UNU-WIDER:

Ozturk, I., \& Acaravci, A. (2013). The Long-run and Causal Analysis of Energy, Growth, Openness and Financial Development on Carbon Emissions in Turkey. Energy Economics, 36, 262-267.

Pandey, S., \& Mishra, M. (2015). CO2 Emissions and Economic Growth of SAARC Countries: Evidence from a Panel VAR Analysis. World Journal of Applied Economics, 1(2), 23-33. doi:10.22440/EconWorld.J.2015.1.2.SP.0009

Parker, S., \& Bhatti, M. I. (2020). Dynamics and Drivers of Per capita CO2 Emission in Asia. Energy Economics, 89, 1-11.

Pesaran, M. H. (2004). General Diagnostic Tests for Cross Section Dependence in Panels. University of Cambridge, Faculty of Economics, Cambridge Working Papers in Economics, No. 0435.

Pesaran, M. H. (2006). Estimation and Inference in Large Heterogeneous Panel with Multifactor Error Structure. Journal of Econometric Society, 74(4), 967-1012.

Pesaran, M. H. (2007). A Simple Unit Root Test in the Presence of Cross-Section Dependence. Journal of Applied Economics, 22, 265-312.

Pesaran, M. H., \& Yamagata, T. (2008). Testing Slope Homogeneity in Large Panels. Journal of Econometrics, 142(2008), 50-93.

Rahman, M. M., Saidi, K., \& Mbarek, M. B. (2020). Economic Growth in South Asia: The Role of CO2 Emissions, Population Density and Trade Openness. Heliyon, 6(5), e03903. doi:10.1016/j.heliyon.2020.e03903

Roy, M., Basu, S., \& Pal, P. (2017). Examining the Driving Forces in Moving Toward a Low Carbon Society: An Extended STIRPAT Analysis for a Fast Growing Vast Economy. Clean Technologies and Environmental Policy, 19(9), 2265-2276.

Salahuddin, M., Alam, K., \& Ozturk, I. (2016). The Effects of Internet Usage and Economic Growth on CO2 Emissions in OECD Countries: A Panel Investigation. Renewable and Sustainable Energy Reviews, 62, 1226-1235.

Salahuddin, M., Alam, K., Ozturk, I., \& Sohag, K. (2018). The Effects of Electricity Consumption, Economic Growth, Financial Development and Foreign Direct Investment on CO2 Emissions in Kuwait. Renewable and Sustainable Energy Reviews, 81, 2002-2010.

Salahuddin, M., Gowb, J., Ali, I., Hossain, R., Al-Azami, K. S., Akbar, D., et al. (2019). Urbanization-Globalization-CO2 Emissions Nexus Revisited: Empirical Evidence from South Africa. Heliyon, 5(e01974). doi:10.1016/j.heliyon.2019.e01974

Salim, R. A., Rafiq, S., \& Shafiei, S. (2017). Urbanization, Energy Consumption, and Pollutant Emissions in Asian Developing Economies: An Empirical Analysis. ADBI Working Paper Series, 718.

Sarkodie, S. A. (2018). The Invisible Hand and EKC Hypothesis: What are the Drivers of Environmental Degradation and Pollution in Africa? Environmental Science and Pollution Research, 25(22), 21993-22022. doi:10.1007/s11356-018-2347-x

Sarkodie, S. A., \& Strezov, V. (2018). Assessment of Contribution of Australia's Energy Production to CO2 Emissions and Environmental Degradation using Statistical Dynamic Approach. Science of the Total Environment, 639, 888-899.

Shaari, S., Karim, Z. A., \& Abidin, N. Z. (2020). The Effect of Energy Consumption and National Output on CO2 Emission: Using a Panel ARDL Analysis. Sustainability, 12, 1-12.

Shabani, Z. D., \& Shahnazi, R. (2019). Energy Consumption, Carbon Dioxide Emissions, Information and Communications Technology, and Gross Domestic Product in Iranian Economic Sectors: A Panel Causality Analysis. Energy, 1064-1078. 
Shahbaz, M., Balsalobre-Lorente, D., \& Sinha, A. (2019). Foreign Direct Investment-CO2 Emissions Nexus in Middle East and North African countries: Importance of Biomass Energy Consumption. Munich Personal RePEc Archive, MPRA Paper No. 91729, 1-48.

Shahbaz, M., Jam, F. A., Bibi, S., \& Loganathan, N. (2016). Mutivariate Granger Causality between $\mathrm{CO} 2$ Emissons, Energy Intensity and Economic Growth in Portugal: Evidence from Cointegration and Causal Analysis. Technological and Economic Development of Economy, 22(1), 47-74. doi:10.3846/20294913.2014.989932

Shahbaz, M., Lean , H. H., \& Shabbir, M. S. (2012). Environmental Kuznets Curve Hypothesis in Pakistan: Cointegration and Granger Causality. Renewable Sustainable Energy Review, 16, 2947-2953.

Shahbaz, M., Mahalik, M. K., Shahzad, S. J. H., \& Hammoudeh, S. (2019). Testing the GlobalizationDriven Carbon Emissions Hypothesis: International Evidence. International Economics.

Shahbaz, M., Shahzad, S. J. H., \& Mahalik, M. K. (2018). Is Globalization Detrimental to CO2 Emissions in Japan? New Threshold Analysis. Environmental Modeling \& Assessment, 23(5), 557-568.

Shahbaz, M., \& Sinha, A. (2018). Environmental Kuznets Curve for CO2 Emission: A Literature Survey. Munich Personal RePEc Archive, MPRA Paper No. 86281, 1-83.

Shaheen, A., Sheng, J., Arshad, S., Salam, S., \& Hafeez, M. (2019). The Dynamic Linkage between Income, Energy Consumption, Urbanization and Carbon Emissions in Pakistan. Political Journal of Environmental Studies, 29(1), 267-276. doi:10.15244/pjoes/95033

Sharma, S., Kishan, R., \& Doig, A. (2014). Low-carbon Development in South Asia: Leapfrogging to a Green Future. Retrieved from Christian Aid:

Swamy, P. A. (1970). Efficient Inference in a Random Coefficient Regression Model. Journal of the Econometric Society, 38(2), 311-323.

TERI. (2019). Scoping Study for South Asia Air Pollution. Retrieved from The Energy and Resources Institute: www.teriin.org

Uddin, M., \& Wadud, A. (2014). Carbon Emission and Economic Growth of SAARC Countries: A Vector Autoregressive (VAR) Analysis. International Journal of Business and Management Review, 2(4), 7-26.

United Nations. (2019). World Economic Situation and Prospects 2019. Retrieved from United Nations, New York:

Urhie, E., Afolabi, A., Afolabi, A., Matthew, O., Osabohien, R., Ewetan, O., et al. (2020). Economic Growth, Air Pollution and Health Outcomes in Nigeria: A Moderated Mediation Model. Cogent Social Sciences, 6(1). doi:10.1080/23311886.2020.1719570

Wang, S., Wang, J., Li, S., Fang, C., \& Feng, K. (2019). Socioeconomic Driving Forces and Scenario Simulation of CO2 Emissions for a Fast-developing Region in China. Journal of Cleaner Production.

Westerlund, J. (2007). Testing for Error Correction in Panel Data. Oxford Bulletin of Economics and Statistics, 69(6), 709-748.

World Bank. (2019a). Exports Wanted: South Asia Economic Focus (April). Retrieved from World Bank, Washington, DC 20433: www.worldbank.org

World Bank. (2019b). Rethinking Decentralization: South Asia Economic Focus (October). Retrieved from World Bank, Washington, DC: www.worldbank.org

World Bank. (2019c). World Development Indicators. Retrieved from https://data.worldbank.org/data-catalog/world-development-indicators

Yang, N., Zhang, Z., Xue, B., Ma, J., Chen, X., \& Lu, C. (2018). Economic Growth and Pollution Emission in China: Structural Path Analysis. Sustainability, 10(7), 2569. doi:10.3390/su10072569

Yazdi, K. S., \& Dariani, A. G. (2019). CO2 Emissions, Urbanisation and Economic Growth: Evidence from Asian Countries. Economic Research-Ekonomska Istraživanja, 32(1), 510-530. doi:10.1080/1331677x.2018.1556107

Zhou, Y., Fu, J., Kong, Y., \& Wu, R. (2018). How Foreign Direct Investment Influences Carbon Emissions, Based on the Empirical Analysis of Chinese Urban Data. Sustainability, 10(7), 2163. 
